How to cite this article:

Hamzah, M. H. I., Baharom, F., \& Mohd, H. (2019). An exploratory study for investigating the issues and current practices of service-oriented architecture adoption. Journal of Information and Communication Technology, 18(3), 273-304.

\title{
AN EXPLORATORY STUDY FOR INVESTIGATING THE ISSUES AND CURRENT PRACTICES OF SERVICE-ORIENTED ARCHITECTURE ADOPTION
}

\author{
${ }^{1}$ Mohd Hamdi Irwan Hamzah, ${ }^{2}$ Fauziah Baharom \& ${ }^{2}$ Haslina Mohd \\ ${ }^{I}$ Faculty of Computer Science and Information Technology, \\ Universiti Tun Hussein Onn Malaysia, Malaysia \\ ${ }^{2}$ School of Computing, Universiti Utara Malaysia, Malaysia
}

hamdi@uthm.edu.my;fauziah@uum.edu.my; haslina@uum.edu.my

\begin{abstract}
Service-Oriented Architecture (SOA) is an approach that can be used to integrate different services across operating systems, platforms, languages, and networks which offer some benefits. However, many organizations fail to fully utilize SOA because the adoption processes are still immature. Therefore, an exploratory study was conducted to investigate current issues and practices of SOA adoption, the use of maturity levels for assessing SOA adoption, and the importance of information technology (IT) and business benefits in SOA adoption. Thus, the Grounded Theory approach was adapted in this study which involved seven software development companies in Malaysia. In this study, 14 SOA practitioners with at least three years of experience in SOA development were interviewed. The collected data was analyzed through three main coding stages: open, axial and selective coding. The theory which emerged from this study revealed SOA adoption issues, current practices, maturity levels,
\end{abstract}


IT and business benefits. The study managed to identify five main issues in SOA adoption which were knowledge, infrastructure, costing, readiness, and documentation issues. The study also portrayed five best practices related to technology, framework, platform, standards, and tools. In addition, results from the study showed five IT and business benefits, consecutively. The findings from the study have led to theories formulation on SOA adoption which may assist researchers and SOA assessors to continuously improve the quality and maturity of SOA adoption in the future.

Keywords: Grounded theory, maturity level, service-oriented architecture adoption, software engineering.

\section{INTRODUCTION}

In general, service-oriented architecture (SOA) is an advance software engineering concept that enables organizations to easily integrate systems, data, applications and processes through the linking of services. Organizations are adopting SOA because it provides several benefits such as reusability, integration, and cost reduction (El-gayar \& Deokar, 2013). However, Aljazzaf, Capretz, and Perry (2016) highlighted that SOA adoption rates are falling and SOA is considered dead. These could be happening due to confusion about SOA concepts among SOA practitioners (Aldris, Nugroho, Lago, \& Visser, 2013).

SOA adoption involves the migration process of a legacy system which is able to disturb the social and technological structures of organizations (Meier, 2006). This migration process encompasses the introduction of new technologies, concepts and principles of software development, IT management and IT architecture (Ciganek, Haines, \& Haseman, 2009). The organization's resources (e.g. employee, technology, workflow, etc.) will be affected and a proper organizational redesign (e.g. individual and culture) is needed in order to adopt SOA successfully. Hence, SOA adoption is not an easy process as it requires changes and well-defined planning in order to perform the migration process successfully. The possibility of reusing services has become the most common reason for SOA adoption (Niklas, Greenyer, \& Schneider, 2015). In addition, it also offers some benefits such as cost reduction, flexibility, and faster reconfiguration of business processes which are valuable for organizations (Meier, 2006).

Nevertheless, there are many organizations that are still unwilling to adopt SOA and some organizations fail to achieve anticipated benefits of the 
adoption (Baghdadi, 2014). The reluctance to adopt SOA may be due to the immaturity of the SOA practices and uncertainty on how to adopt SOA (Basias, Themistocleous \& Morabito, 2015). Furthermore, there is limited number of works which provides a clear guideline for SOA adoption processes besides a lack of empirical evidence on SOA adoption that can be used to improve SOA adoption practices. Therefore, an exploratory study was conducted to investigate the current practices of SOA adoption processes performed by software development companies in Malaysia. Moreover, the study also intended to determine issues, benefits, and maturity levels of SOA adoption. This study was performed using Grounded Theory approach which involved fourteen (14) SOA practitioners. The following are the research questions constructed as a starting point to perform Grounded Theory:

1. What are the issues in SOA adoption?

2. What are the current practices that influence maturity in SOA adoption?

3. What are the maturity levels that practitioners must go through in order to adopt SOA?

4. What are the important benefits of SOA adoption?

The following objectives are constructed in order to perform Grounded Theory:

1. To determine the issues in SOA adoption.

2. To determine current practices that influence the maturity of SOA adoption.

3. To determine maturity levels that practitioners must go through in SOA adoption.

4. To determine the importance of IT and business benefits in SOA adoption.

The contributions of this study includes (1) important issues in SOA adoption processes, (2) implications of findings on theory, best practices, IT and business benefits, and maturity levels of SOA adoption, and (3) the successful application of the Grounded Theory method in the SOA domain.

\section{OVERVIEW OF SERVICE-ORIENTED ARCHITECTURE ADOPTION}

SOA is a paradigm or approach that describes how services should communicate with each other in a loosely-coupled way of solving business problems. Meanwhile, SOA adoption is a process of migrating a legacy system into a 
service-oriented based application. Previously, many organizations adopted SOA in order to obtain benefits offered by SOA (Meier, 2006). Thus, it has inspired this study to investigate on the current practices of SOA adoption and determine its benefits which can be categorized into two: Information Technology (IT) and business (Erl, 2005). According to Erl (2005), IT benefits are concerned with the design principles of SOA, while business benefits help organizations in better planning in order to achieve their business objectives.

Generally, many people agree that the process of migrating legacy systems into SOA could be done by simply exposing the legacy application logic to create services. However, this might not be true as the process of exposing the logic of legacy systems is not easy and besides, SOA adoption introduces several technical challenges such as change in business logic, access to software codes, documentation for legacy systems, and an investment in domain expertise to understand and change an organization's legacy system (Abdul Manan, 2013; Kontogiannis et al., 2007). Moreover, many organizations have failed and are unwilling to adopt SOA due to immature practices (Konigsberger, Silcher, \& Mitschang, 2014; Kontogiannis et al., 2007). Therefore, assessing the maturity of SOA adoption is certainly required to ensure that the right practices are performed during the adoption process.

\section{Service-Oriented Architecture Adoption Maturity Model}

Although many organizations are choosing SOA for capitalizing its benefits, yet academic research related to SOA adoption maturity are still limited. The closest works that attempted to provide SOA guidelines were researches on SOA maturity model. Basically, SOA maturity model was constructed by the industry and academia in order to establish a long-standing SOA vision and SOA maturity perspective and governance support model and also as a roadmap and an evaluation tool for SOA adoption (Pulparambil \& Baghdadi, 2016). According to Oracle (2013), and Inaganti and Aravamudan (2007), an SOA maturity model should provide measurements for evaluating both the SOA maturity and adoption across the enterprise. However, the majority of the SOA maturity models such as SIMM, Welke's Model, and SOAMM were mainly focused on maturity levels. These model were constructed based on CMMI levels (e.g. initial, manage, define, quantitatively manage, and optimize) and did not provide measurements on SOA adoption. Moreover, existing models did not provide detailed explanations on activities and processes for evaluating SOA adoption.

In addition, the evaluation dimensions of existing SOA maturity models are mainly focused on management aspects such as architecture, information, 
business processes, infrastructure, engineering methods, and governance (Mazzarolo, Martins, Toffanello, \& Puttini, 2015). Previous models lacked assessments of SOA that underlie IT perspectives in supporting business processes which can cause organizations to fail to achieve the goals and benefits of adoption (Aldris et al., 2013). The failure to appropriately measure IT benefits can also lead to the failure of being resilient towards supporting business goals in SOA adoption (Aldris et al., 2013).

It is indisputable that previous researchers had identified that the majority of existing SOA maturity models were developed by industry experts and very few were derived from empirical research (Abdul Manan, 2013; Joachim, Beimborn \& Weitzel, 2011). Furthermore, this study also found that empirical researches that discussed SOA adoption practices, from initiation to full adoption from the perspective of SOA practitioners were still limited. These researches were certainly important as the findings could be used to guide practitioners and researchers to make improvements on SOA adoption. Therefore, an exploratory study was performed to investigate the current practices of SOA adoption among practitioners in Malaysia in order to identify issues, practices, maturity levels, and IT and business benefits. Findings from this study would be beneficial to other researches focused on improving SOA adoption and constructing maturity models.

\section{METHODOLOGY}

An exploratory study is normally performed to discover, describe, validate, and understand processes, activities, and characteristics of a current phenomenon in order to extend or develop new theories or methods to improve current practices (Shafinah, Fauziah, Aziz, Jamaiah \& Haslina, 2016). This exploratory study was conducted by way of the Grounded Theory approach (Glaser \& Strauss, 1967). This study aimed to investigate the issues, best practices, maturity levels, and benefits of SOA adoption based on SOA practices in Malaysia. The Grounded Theory is one of the most effective and broadly used approaches in qualitative research with the purpose of helping researchers identify what's going on in a real situation of SOA adoption from the perspectives of IT and business benefits. Grounded Theory is a systematic approach for generating a theory through data collection and data analysis. Glaser (1992) defined Grounded Theory as a general research methodology for data analysis that is associated with data collection through several systematic stages in order to generate a theory. The Grounded Theory approach has been employed, adapted, and refined in multiple research domains 
such as administration, nursing, and software engineering (José, Osinski, \& Hermann, 2017). It provides researchers with a systematic approach on how to determine categories under the study, how to identify the relationship between categories, and how to establish connections between them. Results from the rigorous process of constant comparison will generate a substantive theory from a broad array of data. This theory can be used to aid researchers to clearly understand a phenomenon, enables researchers to develop insights about a problem under investigation without prior hypothesis and also allows the use of a small sample size (Cao \& Ramesh, 2008).

This approach consists of flexible strategies that encompass repetitive actions between qualitative data collection, data analysis, and theory generation (Charmaz, 2000). This repetitive cycle continues up to the point of data saturation. This process stops when there is no new theoretical data or new properties of core categories arising during the theory development process (Glaser \& Strauss, 1967). Due to the cyclical process, data analysis starts early, long before all data are fully collected. Furthermore, data analysis for the Grounded Theory approach consists of three major phases which are: open coding, axial coding, and selective coding. The first phase in Grounded Theory data analysis is open coding or initial coding where this phase focuses on the breaking down of data into distinct units of meaning (Charmaz, 2000). The second phase which is axial coding involves the process of making the connections between codes produced from the previous phase in order to form categories (Charmaz, 2000). This phase helps to understand conditions that produce the categories, context, interactions, and consequences. The third stage is selective coding where categories are integrated based on their relationship and researchers at this point will be able to elaborate substantive theoretical propositions (Hoda, Noble \& Marshall, 2012). In using Grounded Theory, research questions need to be formulated during the research process and not from an extensive literature review done in advance, prior to the initiation of the research (Glaser, 1992). There were five (5) main activities performed in conducting this explorative study which were question development, sampling, data collection, data analysis, and memoing. These activities will be discussed further in the next sub sections.

\section{Question Development}

The contents of the instrument were obtained from previous works such as from Abdul Manan (2013) and Veger (2008). Questions were modified in order to suit the study. The open-ended questions for the semi-structured interview was constructed to allow respondents to include more information, such as their feelings, attitude, and understanding of the subject. This allowed 
the researchers to better access the respondents' true feelings on an issue, including challenges and best practices. Throughout the data collection, some questions were added while others were removed for the second phase of the interview. There were five (5) main sections in the instrument which were i) demographic information, ii) SOA adoption issues, iii) SOA adoption best practices, iv) SOA adoption maturity levels, and v) SOA adoption benefits (refer Appendix A).

\section{Sampling}

Purposive sampling was used to identify the appropriate respondents for this study. The samples were chosen from a group of experts and SOA practitioners in Malaysia. The main constraint of selecting these software practitioners as respondents was that they were very busy and occupied with their daily work activities and could not be reached easily. Consequently, this sampling technique was appropriate since it was intended to be used when only a limited number or category of people can be approached (Sekaran \& Bougie, 2010). Furthermore, this study also proceeded with theoretical sampling after the first categories were identified in order to assist in determing future data based on current data analysis.

Among the criteria in the selection of the respondents was that they must have had at least three years of experience in SOA implementation. The number of respondents for this study were based on data saturation. The study stopped at 14 respondents because no new data emerged at this stage. This circumstance was parallel to the Grounded Theory introduced by Glazer and Straus (1967). The number of respondents for this study which was 14 also corresponded with the findings of Guest, Bunce and Johnson (2006) who found that 12 interviews were sufficient to achieve data saturation.

\section{Data Collection and Analysis}

The study performed data collection repeatedly until a theory emerged or up to the point of data saturation such as shown in Figure 1. The study terminated the data collection when there were no new data which could be identified from the interviews. Glaser and Strauss (1967) stated that the collection of data must be focused on conceptualization while using a comparative method. The in-depth semi-structured interviews together with open-ended questions were conducted for nearly one and a half hours. The scope of data collection covered only five states in Malaysia: Penang, Kedah, Selangor, Putrajaya, and Perlis because these states could provide experts related to the SOA domain and also due to cost constraints. 


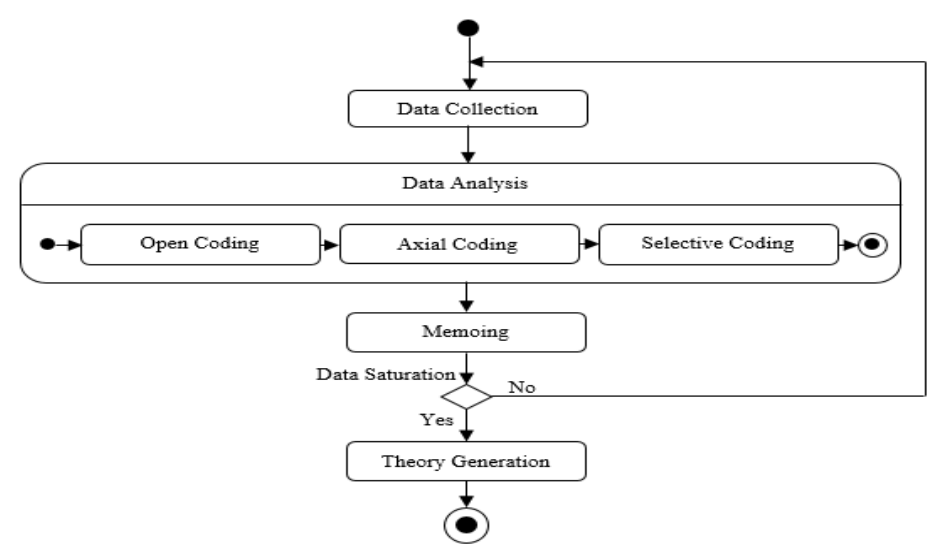

Figure 1. Grounded Theory Data Analysis and Collection Process.

Data analysis was performed through three main stages which were Open, Axial, and Selective Coding. The Open Coding stage, was the first stage which was to identify all important data that were obtained based on the interview sessions. The outcome of this stage was "Open Codes", also referred to as substantive coding (Jovanovic, Mas, Mesquida \& Lali, 2017). The next stage, known as Axial Coding where open codes were grouped into a specific concept at this stage. The Concept is the naming of an emergent social pattern grounded in the research data (Glaser \& Holton, 2007). The third stage, namely Selective Coding was executed to produce related selected categories based on a group of SOA adoption concepts. Towards the end, the final theory of the SOA adoption was constructed. Throughout the data collection and data analysis of the study, the researcher also took notes or wrote memos during the process of interviewing the respondents.

\section{FINDINGS}

This section reports on the findings of the study which include: i) demographic information, ii) SOA issues, iii) SOA adoption practices, iv) maturity levels of SOA adoption, and v) SOA benefits.

\section{Demographic Information}

This section describes the background of the respondents and their organizations based on their respective positions and years of experience in SOA-based application development. Table 1 describes the frequency and percentages of the respondents according to their positions, years of experience, and organization sectors. 


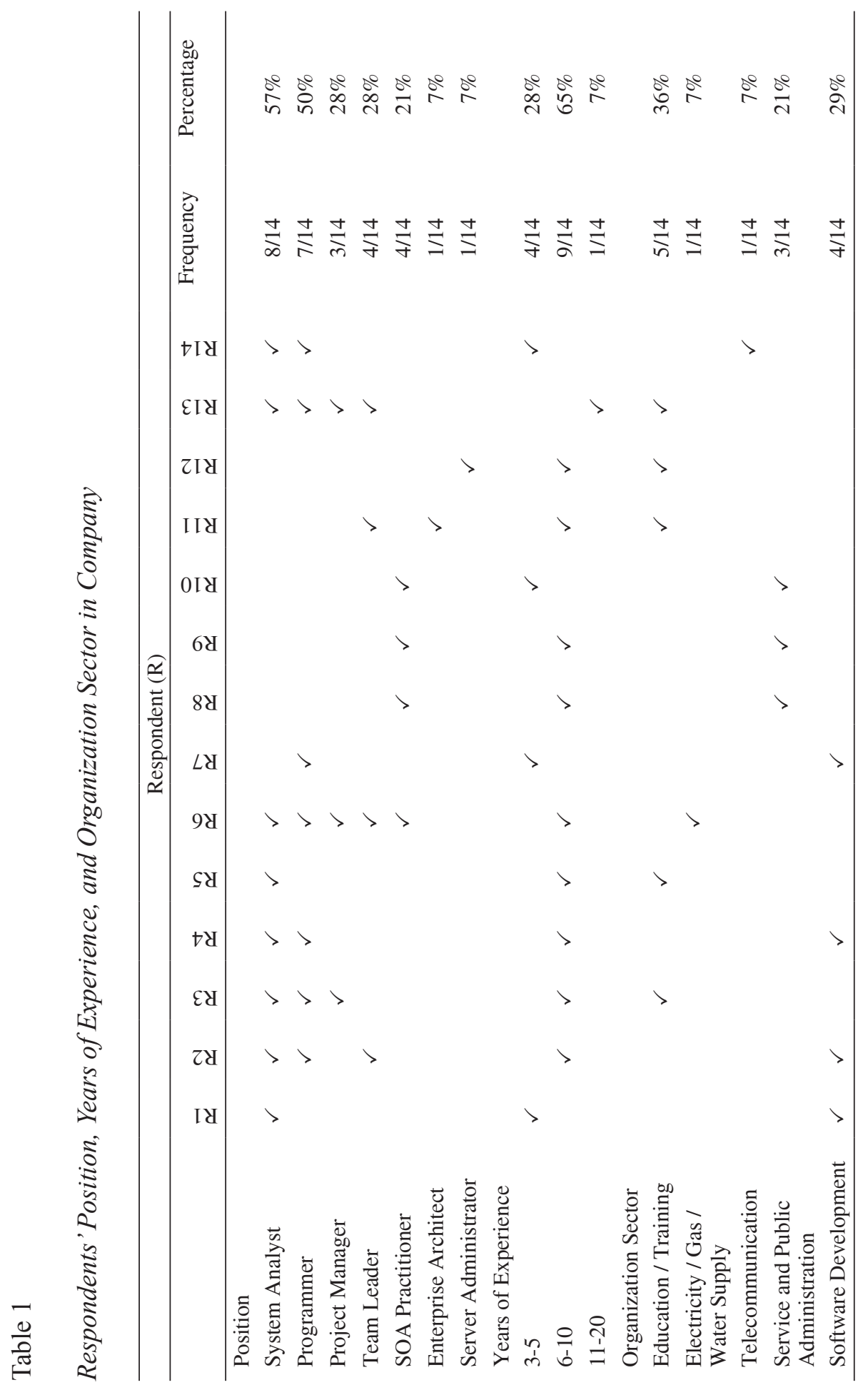


Based on the demographic information presented in Table 1, this study assured that the respondents had at least three years of experience in order to be legitimated as experts. Several of the respondents also had to undergo job rotation where they had to work in several positions. The experience gained from holding various positions could enhance their knowledge of SOA adoption which in turn could provide this study with more information and relevant data. The respondents from different organization sectors were also interviewed in order to get a variety of opinion from different environments. In conclusion, the respondents had enough experience and worked in multiple positions and organization sectors which qualified them to be experts in this study. The next subsection will discuss SOA adoption issues identified in this study.

\section{Service-Oriented Architecture Adoption Issues}

This section provides the findings on issues related to SOA adoption which were identified in this study. Based on the interview, all respondents agreed with the importance of identifying issues on SOA adoption. They stated that these issues needed to be identified first in order to avoid potential problems. Table 2 shows analyzed results of the initial, axial, and selective coding for SOA adoption issues as specified by the respondents in order to be successful in SOA adoption which answered the first research question of this exploratory study.

Table 2

Initial, Axial, and Selective Coding in SOA Adoption Issues

\begin{tabular}{|c|c|c|c|}
\hline $\begin{array}{l}\text { Selective } \\
\text { Coding }\end{array}$ & $\begin{array}{l}\text { Axial } \\
\text { Coding }\end{array}$ & $\begin{array}{l}\text { Initial } \\
\text { Coding }\end{array}$ & Respondent \\
\hline \multirow[t]{2}{*}{$\begin{array}{l}\text { SOA } \\
\text { adoption } \\
\text { issues }\end{array}$} & $\begin{array}{l}\text { SOA } \\
\text { knowledge }\end{array}$ & $\begin{array}{l}\text { Difficulty in learning SOA practices; } \\
\text { Difficulty in understanding SOA } \\
\text { training; SOA concept confusion; } \\
\text { Lack of time to learn about SOA; } \\
\text { Difficulty in exploring SOA. }\end{array}$ & $\begin{array}{l}\text { R1, R4, R5, R6, } \\
\text { R8, R9, R10, } \\
\text { R11, R12, R13, } \\
\text { R14 }\end{array}$ \\
\hline & $\begin{array}{l}\text { SOA } \\
\text { infrastructure }\end{array}$ & $\begin{array}{l}\text { System underutilized; Difficulty } \\
\text { in determining system usage; } \\
\text { Underutilized technology; } \\
\text { Underutilized ESB; Complex } \\
\text { system; Provide dynamic } \\
\text { infrastructure; Expensive } \\
\text { infrastructure; Infrastructure cost. }\end{array}$ & $\begin{array}{l}\text { R3, R6, R7, R8, } \\
\text { R9, R10, R11 }\end{array}$ \\
\hline
\end{tabular}




\begin{tabular}{|c|c|c|c|}
\hline $\begin{array}{l}\text { Selective } \\
\text { Coding }\end{array}$ & $\begin{array}{l}\text { Axial } \\
\text { Coding }\end{array}$ & $\begin{array}{l}\text { Initial } \\
\text { Coding }\end{array}$ & Respondent \\
\hline & $\begin{array}{l}\text { SOA } \\
\text { readiness }\end{array}$ & $\begin{array}{l}\text { Agency readiness evaluation; } \\
\text { Vendor problem; Hosting problem; } \\
\text { Party involved; Agency readiness; } \\
\text { Readiness management; Integration } \\
\text { is not ready }\end{array}$ & $\begin{array}{l}\text { R8, R9, R10, } \\
\text { R11, R12, R13 }\end{array}$ \\
\hline & SOA costing & $\begin{array}{l}\text { Cost by the agency; Cost allocation; } \\
\text { Expensive individual hub; Cost to } \\
\text { anticipate SOA; Cost for system } \\
\text { integration; Determine the cost } \\
\text { bearer; Management buy-in } \\
\text { problem. }\end{array}$ & $\begin{array}{l}\text { R6, R8, R9, } \\
\text { R10, R11 }\end{array}$ \\
\hline & $\begin{array}{l}\text { SOA } \\
\text { documentation }\end{array}$ & $\begin{array}{l}\text { Insufficient documentation; No } \\
\text { documentation; Lack of staff to do } \\
\text { documentation; Late documentation; } \\
\text { Outdated documentation. }\end{array}$ & $\begin{array}{l}\text { R5, R6, R12, } \\
\text { R13, R14 }\end{array}$ \\
\hline & $\begin{array}{l}\text { SOA } \\
\text { development }\end{array}$ & $\begin{array}{l}\text { Lack of SOA development method; } \\
\text { Development focus; SOA project } \\
\text { timeline; Choosing the right SOA } \\
\text { practices; Multiple tasks at a time. }\end{array}$ & $\begin{array}{l}\text { R3, R4, R7, } \\
\text { R11 }\end{array}$ \\
\hline & SOA skills & $\begin{array}{l}\text { Lack of SOA skills; Lack of SOA } \\
\text { experts; Limited skills; Unskilled } \\
\text { top management }\end{array}$ & $\begin{array}{l}\text { R5, R12, R13, } \\
\text { R14 }\end{array}$ \\
\hline & $\begin{array}{l}\text { SOA } \\
\text { maintenance }\end{array}$ & $\begin{array}{l}\text { Downtime issues; OS update } \\
\text { issues; Reconnecting new product } \\
\text { issues; System versioning; Time- } \\
\text { consuming. }\end{array}$ & $\begin{array}{l}\text { R6, R12, R13, } \\
\text { R14 }\end{array}$ \\
\hline & $\begin{array}{l}\text { SOA } \\
\text { experience }\end{array}$ & $\begin{array}{l}\text { Lack of SOA development } \\
\text { experience; SOA familiarity; Lack } \\
\text { of SOA adoption experience. }\end{array}$ & $\mathrm{R} 2, \mathrm{R} 4, \mathrm{R} 11$ \\
\hline & $\begin{array}{l}\text { Communication } \\
\text { and } \\
\text { collaboration }\end{array}$ & $\begin{array}{l}\text { Communication issues; } \\
\text { Collaboration issues; Responsibility } \\
\text { issues. }\end{array}$ & R8, R9, R10 \\
\hline & $\begin{array}{l}\text { User } \\
\text { requirements }\end{array}$ & $\begin{array}{l}\text { Unclear user requirements; } \\
\text { Changing user requirements; } \\
\text { Endless requirements; Unnecessary } \\
\text { user requirements; Underutilized } \\
\text { requirements. }\end{array}$ & R3, R6, R11 \\
\hline
\end{tabular}




\begin{tabular}{llll}
\hline $\begin{array}{c}\text { Selective } \\
\text { Coding }\end{array}$ & \multicolumn{1}{c}{$\begin{array}{c}\text { Axial } \\
\text { Coding }\end{array}$} & \multicolumn{1}{c}{$\begin{array}{c}\text { Initial } \\
\text { Coding }\end{array}$} & Respondent \\
\hline & Migration & $\begin{array}{l}\text { Legacy system maintenance; } \\
\text { Legacy system migration; Learning } \\
\text { process migration; Lack of interest } \\
\text { to migrate. }\end{array}$ & R5, R6, R11 \\
& Network & $\begin{array}{l}\text { Internet connection issues; Network } \\
\text { coverage issues. }\end{array}$ & R2, R11 \\
& $\begin{array}{l}\text { No proper logging; Undetected } \\
\text { errors. }\end{array}$ & R5 \\
& $\begin{array}{l}\text { Human issues; Acts and legislation } \\
\text { issues; Privacy issues; Unshared } \\
\text { data issues. }\end{array}$ & R7 \\
& & & \\
\hline
\end{tabular}

Based on Table 2, there are fifteen (15) SOA adoption issues that have been identified in this study. However, only five (5) issues were considered as main issues in SOA adoption and the rest were classified as other issues. The following shows the examples of quotes for SOA knowledge adoption issues. Data obtained from the interviews suggested that SOA knowledge issues

was the most stated issue. The SOA knowledge related issues or problems could either speed up or delay SOA adoption within the organization. The issues that were normally faced by the majority of the respondents included the process of learning the technology, framework, platform and the concept of SOA adoption. An example of the descriptions on how knowledge could speed up or delay SOA adoption is as follows: "...how we can adapt to change?, How quickly we can learn? Right now mostly because we rarely have the time to learn, kind of, ok we have a year to learn the language, we use it later next year. Usually, we learn while developing the system..." (R3). The following statements made by another respondent is also in line with the above statements: "...It takes time and that maybe more of a challenge for us. That's maybe from a knowledge point of view because we have to do it by ourselves, we have to explore ourselves. We do not involve vendor so it takes time." (R13). This is the statement made by a respondent from MAMPU (the central agency that is responsible in driving other government agencies in Malaysia to adopt SOA): "...Any agency that wants to start the SOA initiative, knowledge is always the issue. The knowledge is needed to implement SOA. To develop a web service is one issue and to develop a SOA is another issue along with the concept. At the early stage it really requires an exposure and hands-on. As for MAMPU we need to know about SOA, maybe through the reading of literature and books." (R9). 
Another respondent also stressed that there were other practitioners who were only familiar with SOA implementation instead of the theory. "... From the implementation wise they did implement web service but maybe they did not know it was part of SOA." (R8). Furthermore, another respondent declared that the issue on SOA knowledge was because the developers were unable to fully utilize SOA. The reason was that they were new to the SOA platform and thus were unable to fully utilize SOA. This is the statement: “... But in this case we still did not fully utilize it because the developers are still new to PHP. So that's why other developers start to use the framework because it can simplify our work..." (R5). As for the newcomers, knowledge would be the major concern at the early stage of SOA adoption as they had to learn new technology. This was revealed by a respondent who was always concerned with learning new knowledge as at sometimes it could be very hard instead of easy for them: “... We have to learn a new knowledge regarding to this migration process but on the learning curve we have to be more particular whether it is very steep or not too hard..." (R6). Finally, based on the statement given by the respondents, it indicated that SOA knowledge was the most mentioned issue. This issue was usually encountered during the early stages of SOA adoption. Therefore, if this issue was not resolved properly, it could affect development time and the capability to effectively utilize SOA.

\section{Service-Oriented Architecture Adoption Best Practices}

This section addresses the practitioners' opinions and experiences regarding the SOA adoption process by describing their familiarity towards SOA best practices which they applied in their line of work. Table 3 shows the initial, axial, and selective coding for SOA adoption best practices that the respondents were familiar with. Based on research question 2, identifying best practices was also important to achieve success in SOA adoption.

Table 3

Initial, Axial, and Selective Coding for Best Practices in SOA

\begin{tabular}{|c|c|c|c|}
\hline $\begin{array}{l}\text { Selective } \\
\text { Coding }\end{array}$ & $\begin{array}{c}\text { Axial } \\
\text { Coding }\end{array}$ & $\begin{array}{c}\text { Initial } \\
\text { Coding }\end{array}$ & Respondent (R) \\
\hline $\begin{array}{l}\text { SOA } \\
\text { adoption best } \\
\text { practices }\end{array}$ & $\begin{array}{l}\text { SOA } \\
\text { technology }\end{array}$ & $\begin{array}{l}\text { Web service technology; REST } \\
\text { technology; OPC technology; } \\
\text { FLASK technology; Apache } \\
\text { Thrift technology. }\end{array}$ & $\begin{array}{l}\text { R1, R2, R3, R4, } \\
\text { R5, R6, R7, R8, } \\
\text { R9, R10, R11, R12, } \\
\text { R13, R14 }\end{array}$ \\
\hline
\end{tabular}




\begin{tabular}{|c|c|c|c|}
\hline $\begin{array}{c}\text { Selective } \\
\text { Coding }\end{array}$ & $\begin{array}{c}\text { Axial } \\
\text { Coding }\end{array}$ & $\begin{array}{l}\text { Initial } \\
\text { Coding }\end{array}$ & Respondent (R) \\
\hline & $\begin{array}{l}\text { SOA } \\
\text { framework }\end{array}$ & $\begin{array}{l}\text { Code Igniter framework; } \\
\text { Laravel. framework; Skytel } \\
\text { framework; CAKE framework; } \\
\text {.NET framework; Zend } \\
\text { framework; Java web service } \\
\text { framework; Google App Engine } \\
\text { framework; Google Compute } \\
\text { Engine framework; gSOAP } \\
\text { framework; XML Interface } \\
\text { framework. }\end{array}$ & $\begin{array}{l}\text { R1, R2, R3, R4, } \\
\text { R5, R6, R7, R8, } \\
\text { R9, R10, R11, R12, } \\
\text { R13, R14 }\end{array}$ \\
\hline & $\begin{array}{l}\text { SOA } \\
\text { platform }\end{array}$ & $\begin{array}{l}\text { PHP platform; C\# platform; } \\
\text { Python platform; Node.js } \\
\text { platform; Java platform; VB.net } \\
\text { platform. }\end{array}$ & $\begin{array}{l}\text { R1, R2, R3, R4, } \\
\text { R5, R6, R7, R8, } \\
\text { R9, R10, R11, R12, } \\
\text { R13, R14 }\end{array}$ \\
\hline & $\begin{array}{l}\text { SOA } \\
\text { standard }\end{array}$ & $\begin{array}{l}\text { Web service standard; XML } \\
\text { specification standard; } \\
\text { Messaging specification } \\
\text { standard; Metadata exchange } \\
\text { specification standard; WSI } \\
\text { specification standard; Business } \\
\text { process specification standard; } \\
\text { Security specification standard. }\end{array}$ & $\begin{array}{l}\text { R1, R2, R3, R4, } \\
\text { R5, R6, R7, R8, } \\
\text { R9, R10, R11, R12, } \\
\text { R13, R14 }\end{array}$ \\
\hline & SOA tool & $\begin{array}{l}\text { Postman; Notepad++; Putty; } \\
\text { Eclipse; PyCharm; IBM web } \\
\text { sphere; IDE. }\end{array}$ & $\begin{array}{l}\text { R5, R6, R7, R11, } \\
\text { R12, R13, R14 }\end{array}$ \\
\hline
\end{tabular}

Based on Table 3, there were five (5) SOA adoption practices identified in this study which were SOA technology, SOA framework, SOA platform, SOA standards, and SOA tools.

\section{Service-Oriented Architecture Adoption Maturity Levels}

In the interview, the respondents were also indirectly asked about the maturity levels of SOA adoption in order to get genuine answers. All respondents managed to answer all of the questions related to maturity levels. Table 4 shows the initial, axial, and selective coding for the maturity levels of SOA adoption that were categorized using the Grounded Theory approach.

Based on Table 4, this study identified five (5) maturity levels of SOA adoption which were Initial, Adopted, Implemented, Evaluated, and Optimized. Respondents were queried on the activities that they performed in order to start adopting the SOA until they reached a certain level where their SOAbased application was considered to be fully optimized. 


\section{Table 4}

\section{Initial, Axial, and Selective Coding for Maturity Levels of SOA Adoption}

\begin{tabular}{|c|c|c|}
\hline $\begin{array}{c}\text { Selective } \\
\text { Coding }\end{array}$ & $\begin{array}{l}\text { Axial } \\
\text { Coding }\end{array}$ & $\begin{array}{l}\text { Initial } \\
\text { Coding }\end{array}$ \\
\hline $\begin{array}{l}\text { Maturity } \\
\text { levels } \\
\text { of SOA } \\
\text { adoption }\end{array}$ & Initial level & $\begin{array}{l}\text { Legacy system migration; Individual } \\
\text { awareness on SOA; Top management } \\
\text { awareness on SOA; Migration } \\
\text { instructions coming from top } \\
\text { management; SOA practitioners' } \\
\text { awareness on SOA; IT department's } \\
\text { awareness on SOA; Organization's } \\
\text { awareness on SOA; Product owners' } \\
\text { awareness on SOA; Boss' awareness } \\
\text { on SOA; } \\
\text { Provide training; Hands-on training; } \\
\text { Training in class; Official training; } \\
\text { Knowledge sharing; Workshop; } \\
\text { External training; Transfer training; } \\
\text { Internal training; Project-based } \\
\text { training; Coaching; User manual; } \\
\text { Skills variation among practitioners; } \\
\text { Skillful } \\
\text { practitioners; Skills within the IT } \\
\text { department; Top management did not } \\
\text { have the skills; Technical people are } \\
\text { more skillful; Programming skills; } \\
\text { Coding skills; Skills depend on the } \\
\text { platform; Job rotation; Individual } \\
\text { beliefs; Top management beliefs; SOA } \\
\text { practitioners' beliefs; IT department's } \\
\text { beliefs; } \\
\text { Organizational beliefs; Boss' beliefs; } \\
\text { User beliefs; Individual beliefs. }\end{array}$ \\
\hline
\end{tabular}

Respondent (R)

R1, R2, R3, R4,

R5, R6, R7, R8, R9, R10, R11,

$\mathrm{R} 12, \mathrm{R} 13, \mathrm{R} 14$

Adopted level Organization provides the SOA

R1, R2, R3, R4, environment; Provide the SOA environment; Purchase the SOA R5, R6, R7, R8, R9, R10, R11, infrastructure; Identify SOA best R12, R13, R14 practices.

Implemented level
System based on user requirements;

Capture user requirements;

Modify system based on user requirements; Follow user requirements; Lock requirements; 


\begin{tabular}{|c|c|c|c|}
\hline $\begin{array}{c}\text { Selective } \\
\text { Coding }\end{array}$ & $\begin{array}{c}\text { Axial } \\
\text { Coding }\end{array}$ & $\begin{array}{c}\text { Initial } \\
\text { Coding }\end{array}$ & Respondent (R) \\
\hline & & $\begin{array}{l}\text { Develop system; Present system; Get } \\
\text { used to system; Get approval; Perform } \\
\text { feasibility study; System within scope; } \\
\text { Develop system internally; Plan for } \\
\text { development; Development stage; } \\
\text { Internal system is easy to maintain; } \\
\text { Develop system based on project; } \\
\text { Develop a system requires several } \\
\text { levels; Meeting to show development } \\
\text { progress; Development is within SOA } \\
\text { life cycle; Align system } \\
\text { development with documentation. }\end{array}$ & $\begin{array}{l}\text { R1, R2, R3, R4, } \\
\text { R5, R6, R7, R8, } \\
\text { R9, R10, R11, } \\
\text { R12, R13, R14 }\end{array}$ \\
\hline & $\begin{array}{l}\text { Evaluated } \\
\text { level }\end{array}$ & $\begin{array}{l}\text { Provide SLA; SLA duration; } \\
\text { Performance test; Define SLA; Get } \\
\text { approval; Deploy system; Test system; } \\
\text { Measure system performance; Present } \\
\text { system; Timeline is set to deploy } \\
\text { system; System } \\
\text { deployment is within SOA life cycle. }\end{array}$ & $\begin{array}{l}\text { R1, R2, R3, R4, } \\
\text { R5, R6, R7, R8, } \\
\text { R9, R10, R11, } \\
\text { R12, R13, R14 }\end{array}$ \\
\hline & $\begin{array}{l}\text { Optimized } \\
\text { level }\end{array}$ & $\begin{array}{l}\text { Monitor system; Monitoring is one of } \\
\text { system's life cycle; Maintain system; } \\
\text { Improve system; Transform way to } \\
\text { provide services. }\end{array}$ & $\begin{array}{l}\text { R1, R2, R3, R4, } \\
\text { R5, R6, R7, R8, } \\
\text { R9, R10, R11, } \\
\text { R12, R13, R14 }\end{array}$ \\
\hline
\end{tabular}

\section{Service-Oriented Architecture Adoption Benefits}

In this section, most of the respondents stated that one of their reasons for applying SOA was due to the benefits offered. This showed that the practitioners acknowledged that outcome from the SOA adoption resulted in benefits. The coding for the benefits are presented in Table 5 .

The majority of the respondents stated reusability (92\%) as the SOA adoption benefits, followed by integration (85\%) and cost reduction (85\%). Out of the 14 respondents, 10 of them mentioned accessibility (71\%) and nine chose scalability (64\%), flexibility (64\%), agility (64\%) and maintainability (64\%). The rest of the SOA benefits were business optimization (57\%), IT/business alignment $(57 \%)$, business quality $(50 \%)$, time reduction $(50 \%)$, business transformation (28\%), loose coupling (21\%), separation of concerns $(7 \%)$ and changeability $(7 \%)$. The responses indicated that almost half of the respondents agreed on the same SOA benefits that were proposed earlier in this study. Assertively, 13 out of the 14 respondents agreed that these SOA benefits should be categorized into IT and business benefits. All of them also 
agreed that collaboration between IT and business was extremely important in SOA adoption.

Table 5

Initial, Axial, and Selective Coding for SOA Adoption Benefits

\begin{tabular}{|c|c|c|c|}
\hline $\begin{array}{c}\text { Selective } \\
\text { Coding }\end{array}$ & $\begin{array}{c}\text { Axial } \\
\text { Coding }\end{array}$ & $\begin{array}{c}\text { Initial } \\
\text { Coding }\end{array}$ & Respondent (R) \\
\hline \multirow[t]{3}{*}{$\begin{array}{l}\text { SOA } \\
\text { adoption } \\
\text { benefits }\end{array}$} & IT benefits & $\begin{array}{l}\text { Reusability; Integration; Flexibility; } \\
\text { Agility; Maintainability; } \\
\text { Accessibility; } \\
\text { Changeability; Separation of } \\
\text { concern; } \\
\text { Scalability; Loose coupling. }\end{array}$ & $\begin{array}{l}\text { R1, R2, R3, R4, R5, } \\
\text { R6, R7, R8, R9, } \\
\text { R10, R11, R12, R13, } \\
\text { R14 }\end{array}$ \\
\hline & $\begin{array}{l}\text { Business } \\
\text { benefits }\end{array}$ & $\begin{array}{l}\text { Time reduction; Cost reduction; } \\
\text { Business } \\
\text { optimization; Business quality; } \\
\text { Business } \\
\text { transformation; IT/business } \\
\text { alignment. }\end{array}$ & $\begin{array}{l}\text { R1, R2, R3, R4, R5, } \\
\text { R6, R7, R8, R9, } \\
\text { R10, R11, R12, R13, } \\
\text { R14 }\end{array}$ \\
\hline & $\begin{array}{l}\text { IT and } \\
\text { business } \\
\text { benefit } \\
\text { classification }\end{array}$ & $\begin{array}{l}\text { Categorization of IT and business } \\
\text { benefits; } \\
\text { Collaboration of IT and business } \\
\text { benefits. }\end{array}$ & $\begin{array}{l}\text { R1, R2, R3, R4, R5, } \\
\text { R6, R7, R8, R9, } \\
\text { R10, R11, R12, R13, } \\
\text { R14 }\end{array}$ \\
\hline
\end{tabular}

\section{DISCUSSION}

This section presents a discussion on the objectives of the study and relates its findings to the literature. The study consisted of four main objectives as follows:

Objective 1: To determine issues in SOA adoption.

This section discusses the identified five main issues related to SOA adoption. The issues are SOA knowledge, infrastructure, costing, readiness, and documentation.

\section{Service-Oriented Architecture knowledge}

Most of the respondents indicated knowledge as the common issue encountered in SOA adoption. Similarly, issues related to knowledge had been identified 
in numerous previous studies. Based on the interview, the SOA knowledge issue could be in the form of difficulty in learning SOA practices, difficulty in understanding SOA training, misconception about SOA concepts, lack of time to learn SOA, and difficulty in exploring SOA. Based on the findings discussed earlier, the difficulty in learning SOA practices was based on issues such as identifying SOA best practices that should be implemented in SOA. This issue was similar to what had been stated by Gbaffonou, Lapalme, and Champagne (2015). They stated that there was a lack of research that identified and determined SOA practices. Furthermore, there was still an issue regarding the understanding of SOA concepts as many practitioners considered SOA as merely about development processes such as SOA technology and standards (Aldris et al., 2013). Baghdadi (2014) also pointed out that developers still had misconceptions about SOA because SOA meant different things to different people, such as web services technology or enterprise application integration. Thus, based on literature findings and exploratory findings, it can be concluded that SOA knowledge issues is an important issue that needs to be solved before developing SOA-based applications.

\section{Service-Oriented Architecture infrastructure}

The second major issue which emerged was the SOA infrastructure issue. The SOA infrastructure is one of the first things that should be provided and prepared in order for an information system to become a service system (Welke et al., 2011). The findings in this study such as difficulty to provide a dynamic and powerful SOA infrastructure had been stated in a previous work by Pan et al. (2014). Moreover, the process of providing a global SOA infrastructure which is dynamic, stable with backward compatibility can also incur higher costs (Hsiung, Rivelli \& Hüttenegger, 2012). This statement corresponded to issues identified in this study where respondents stated that providing a good SOA infrastructure would usually be too costly. Hence, an extensive preliminary study has been suggested by the respondents in order to solve this issue. Therefore, an organization should carefully select SOA infrastructure that can be fully utilized based on its project and usage.

\section{Service-Oriented Architecture costing}

In addition, the respondents also mentioned issues related to SOA adoption cost. Issues on cost can be a stumbling block in SOA adoption. The issue such as cost allocation that is needed to provide SOA infrastructure was stated in this interview. This issue was raised by Becker, Buxmann, and Widjaja (2009) where they identified that financing is one of the big issues in SOA adoption. Brien (2009) also stated that inadequate consideration in determining the cost 
for SOA projects could be detrimental to the organization that adopted SOA. Therefore, the issue on cost in SOA adoption requires proper planning and method in order to manage the risk of cost blowout during the development stage and to secure the necessary funding for SOA adoption.

\section{Service-Oriented Architecture readiness}

Based on Grounded Theory, SOA readiness was also identified as one of the main issues in SOA adoption. SOA readiness can be defined as a state where the organization has awareness about SOA concept, recognizes SOA problems, its limitations, cost, and benefits of SOA adoption cited by Abdul Manan, 2013). The SOA readiness evaluation was one of the issues that was stated by the respondents. This issue is in line with previous work by Eckert, Bachhuber, Miede, Papageorgiou, and Steinmetz (2010), where they asserted that there was a need to evaluate SOA readiness in the German banking industry. Furthermore, Abdul Manan (2013) also claimed that the majority of the public sectors in Malaysia were still not SOA ready. Thus, this assertion supported the findings of this study as there was an issue in providing SOA readiness to government agencies. Consequently, it can be argued that the issue of SOA readiness can pose a huge problem in effectively realizing SOA benefits. This is because an organization needs to be SOA ready in order to move towards enterprise-wide SOA.

\section{Service-Oriented Architecture documentation}

Furthermore, this study found that the majority of the respondents also raised issues on SOA-based application documentation. The SOA-based application documentation issue identified in this study were: lack of documentation, no documentation provided, late documentation, and outdated documentation. Graaf, Liang, Tang, and Vliet (2015) stated that if documentation issues were not properly handled, it could lead to a useless software as it was hard to understand. Blomstedt et al. (2014) also identified that this documentation issue required more attention as the method for documenting the system was still limited. Therefore, this study found that the organization still has a problem in providing a system documentation based on the literature and empirical findings.

It can be concluded that, the SOA adoption issues which emerged from this study corresponds to issues stated in the literature. The circumstances have indicated that these issues still remain in the SOA domain and need to be solved in order to successfully adopt SOA. 
Objective 2: To determine the current practices that influence the maturity of SOA adoption.

This section provides a discussion on the five important practices which are SOA technology, framework, platform, standards, and tools.

\section{Service-Oriented Architecture technology}

Basically, the identification of the SOA technology is important as SOA is not merely about web services. SOA does not consist of a single technology only as SOA is actually a paradigm that can handle communication between distributed services across a network. There are varieties of SOA technology such as web service, REST, and others. Previous researchers also mentioned that the identification of SOA technology is important in order to provide a means to realize SOA (Haines \& Haseman, 2009). Hence, SOA technology can be described as one of the important portions of SOA practices.

\section{Service-Oriented Architecture framework}

The second practice that has been identified in this study is the SOA-based application framework. Elia, Laranjeiro, and Vieira (2014) stated that SOAbased application framework is vital in SOA development as it includes all the mechanisms needed to assure interoperable interaction. This study through Grounded Theory, found that the SOA-based application framework provides a ton of readymade features that can be used to aid SOA development. Hence, it is important to identify an appropriate SOA-based application framework that suits the organizational environment.

\section{Service-Oriented Architecture platform}

The third SOA practice is the SOA-based application platform. The SOAbased application platform consists of a language that is used specifically for SOA development. Previous researchers stated that SOA-based application platform is important as it forms the foundation upon which a massive amount of SOA-based applications are developed (Amanatidis \& Chatzigeorgiou, 2016). Moreover, the identification of the SOA-based application platform can also provide SOA practitioners with a selection of platforms to choose from, in order to suit their SOA technology and framework.

\section{Service-Oriented Architecture standards}

SOA standards is the fourth SOA adoption practice that has been identified based on this study. This practice has proven to be vital to the development of 
SOA-based applications as it provides the communication method and channel for services to communicate. Espí-beltrán, Gilart-iglesias, and Ruiz-fernández (2016) identified that SOA standards allows for collaboration between services by sharing information through a standardized communication. So, this study concludes that SOA standards is an obligation in order to provide a communication method for services to interact with each other.

\section{SOA tools}

The last SOA adoption practice is SOA tools. This practice has received mixed reactions among SOA practitioners. They stated that they had automatically used the tools when they applied the SOA-based application framework. However, several SOA practitioners argued that there were other tools that were not included in the framework which had proven to be useful in SOA development. Bluemke (2014) stated that the application of SOA tools in SOA development is important as it can be used to test SOA-based applications. Furthermore, Liu and Chen (2017) also mentioned that tools can help to validate SOA-based applications by generating valid test data. Therefore, this study found that the use of SOA adoption tools is important as it can assist in the SOA development process.

In conclusion, the findings related to SOA adoption best practices is important in order to identify the current practices in SOA. Joukhadar and Rabhi (2015) stated that in order to be successful in SOA adoption, the organization needs to emulate best practices and guidance within the SOA domain. However, even though many have claimed that they have already identified SOA practices, their results did not provide details of the technology, framework, platform or standards that were used (Gbaffonou et al., 2015). Thus this study aims to provide all the information related to SOA practices such as technology, framework, platform, standards and tools applied within the SOA domain in Malaysia.

Objective 3: To determine the maturity levels that practitioners must go through in SOA adoption.

Based on the findings, the study has identified five maturity levels for SOA adoption. This section provides a detailed discussion for each level.

\section{Initial level}

The initial level comprises awareness, training, skills and belief in the effectiveness of SOA adoption. These sub-factors are consistent with the sub- 
factors in the initial level of the Adoption of Innovation concept (Wisdom, Chor, Hoagwood, \& Horwitz, 2014). As for CMMI, the services at this level are usually ad hoc and chaotic where services usually exceed the budget and schedule (CMMI Product Team, 2010). Hence, based on CMMI, Adoption of Innovation concept, and findings from the study, this study identified that this level should focus on SOA knowledge gathering and so as to be able to develop simple and ad hoc services.

\section{Adoption level}

Based on the Adoption of Innovation concept, the second level which is the adopted level must consist of a decision stage, whether to adopt or reject the innovation. If the organization chose to adopt the innovation (SOA), the organization is required to either purchase or provide the technology and apply the innovation standards (Wisdom et al., 2014). In CMMI, this stage is where best practices are identified in order to make sure that success can be repeated and retained (CMMI Product Team, 2010). This statement is in line with the findings in this study whereby the respondents did mention about purchasing and providing SOA infrastructure and that best practices in SOA were identified based on the infrastructure.

\section{Implementation level}

According to previous works (Damanpour \& Daniel-Wischnevsky, 2006), the third level of SOA adoption is referred to as implemented. At this level, the innovation (SOA) should have been integrated within the organization, whilst the adopters are committed to implement the innovation. Meanwhile, CMMI indicated that this level is where best practices are applied and embedded (CMMI Product Team, 2010). Similar outcomes were established in this study whereby the respondents described at this level, that the innovation was business driven and that the SOA best practices were applied in developing the system.

\section{Evaluation level}

The evaluated level of the SOA innovation is based on CMMI because the adoption of innovation concept ends the activities at the implemented level. Nevertheless, it is pointed out in the Adoption of Innovation concept that organizations should make full use of an innovation. In other words, the adopter must apply the innovation until it is fully optimized. So based on CMMI, level 4 establishes quantitative goals for quality and system performance 
evaluation (CMMI Product Team, 2010). This activity has been confirmed by the respondents in this study who stated that they had conducted the system performance testing and defined the SLA. System deployment will come in once they have come to an agreement with the users.

\section{Optimization level}

The final level of the SOA, optimized, is also based on CMMI which focuses on continuous improvement. Based on the Adoption of Innovation concept, the adoption level should be up until the innovation has been fully utilized or optimized (Roger, 1995). Again, the respondents in this study claimed that once the system has been deployed, work on monitoring, maintenance and improvement will surely be carried out. This implies that the practitioners' actions coincide with that of the proposed maturity level by Hamzah, Baharom, and Mohd (2017).

This study has proposed an adoption maturity level based on CMMI and Adoption of Innovation concept. Nevertheless, the levels proposed based on these standards are too general to measure the adoption maturity of SOA. Therefore, by performing Grounded Theory, this study can map the key practices of SOA adoption indicated by the experts onto the proposed adoption maturity level. This process can improve the validity of the proposed level as it is not constructed solely on theoretical findings but also based on empirical findings.

Objective 4: To determine the importance of IT and business benefits for SOA adoption.

All the respondents agreed that they applied SOA because of the benefits it provided. They identified several of the SOA benefits and agreed that it could be classified into IT and business benefits. These IT benefits have also been identified in the previous literature such as the works by Joachim (2011) and Baskerville et al. (2005) where they has identified that IT benefits is consist of reusability, integration, flexibility, agility, and scalability. Furthermore, Anthony, Majid, and Romli (2018) also mentioned that generally IT can contribute towards resolving the sustainable issues such as facilitating the Green software engineering by providing eco-logically-friendly services such as deploying virtual teleconference rather than traveling to attend it. In addition, business benefits have also been stated as important benefits that should be achieved by adopting SOA. The business benefits that have been identified by the respondents were business transformation, business optimization, IT/ 
business alignment, cost reduction, and functionality. Most of these business benefits were identical to the business benefits mentioned by Sonic Software et al. (2005). The similarity in the answers given by the respondents with the proposed SOA adoption benefits could be because the interviewer mentioned several of the benefits during the interview. Nevertheless, this study never emphasized or stressed on the proposed SOA adoption benefits as the respondents had answered the questions based on their experiences.

In addition, based on Grounded Theory, the respondents acknowledged that the IT and business benefits were the outcomes that should be achieved from the SOA adoption. A majority of the respondent also supported the view that the SOA benefits should be categorized into IT and business benefits. All of them added further that the collaboration between IT and business was very important in order to be successful in the SOA adoption. This statement was in line with the previous work where the researchers stated that organizations should focus more on the collaboration between IT and business as this could further improve the outcomes of SOA adoption (Joachim et al., 2011). It can be concluded that, the IT and business benefits identified in this study supported the benefits proposed by Hamzah et al. (2017).

\section{PROPOSED THEORY OF SOA ADOPTION BASED ON GROUNDED THEORY}

In summary, based on the analysis of the Grounded Theory which was employed in the study, it had introduced theories or important factors related to SOA adoption. Figure 2 illustrates the theories or important factors of SOA adoption obtained from the study.

As shown in Figure 2, the study identified three main factors that could contribute to the maturity of SOA adoption. The factors are issues, practices, and benefits. The organizations need to fully understand these factors before they start to adopt the SOA. First, the organizations need to identify issues in SOA adoption in order to avoid any unexpected problems throughout the SOA adoption. Second, best practices in SOA adoption should be identified by the organizations in order to provide the best possible method(s) in developing SOA-based applications. Finally, the outcome or the value of the SOA adoption also needs to be clearly defined so as to reap the full benefits of the adoption. As shown in Figure 2, the identified maturity levels can be used to determine progress and achievement in the SOA adoption. These levels can be used to continuously improve the SOA adoption practices. 


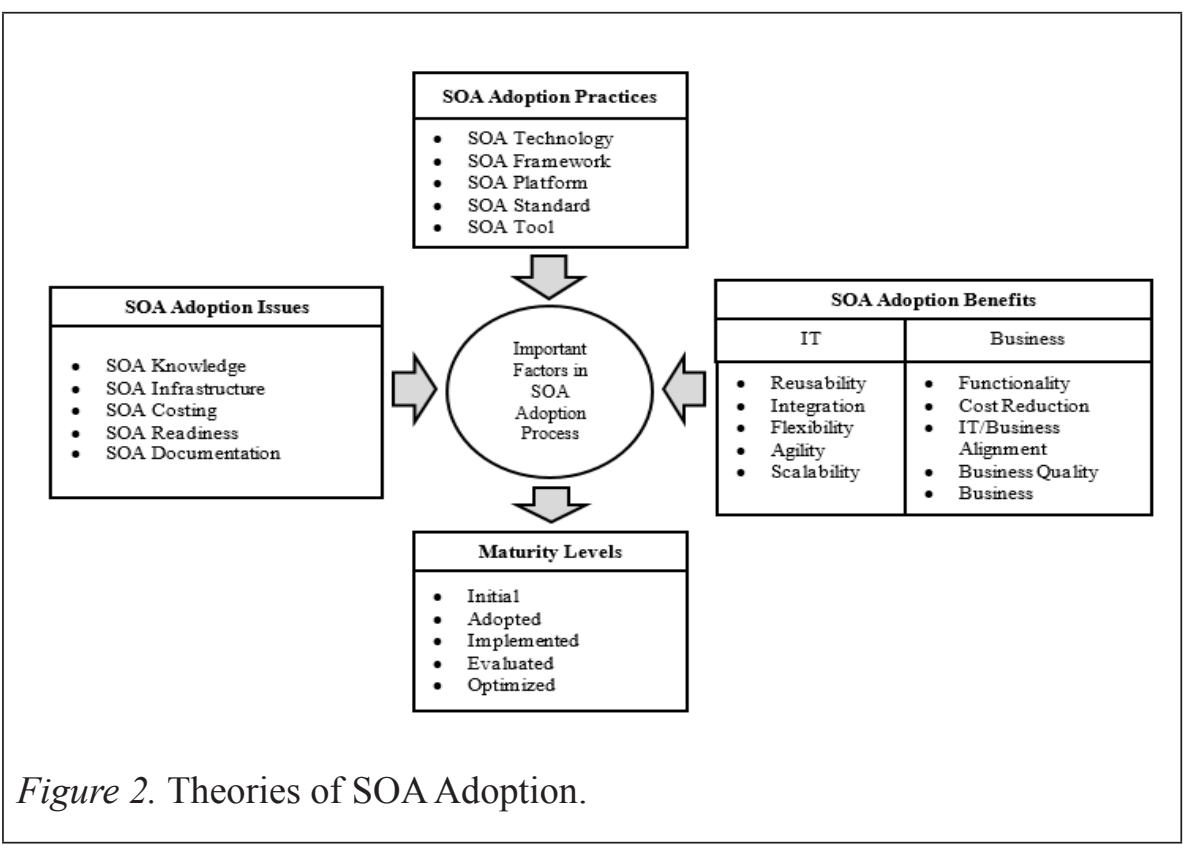

\section{LIMITATIONS}

Since this study is conducted in Malaysia, its findings cannot be generalized to other countries. Moreover, the Grounded Theory approach was never meant to provide a universal theory (Jovanovic et al., 2017). However, the data, such as the SOA best practices, can be improved by performing a quantitative research so that a more precise and rich data can be generated for this purpose. The same method could also be applied in identifying the SOA adoption benefits as the quantitative research could provide a better number of respondents since they can be reached more easily. The Grounded Theory approach provides a method of uncovering theory that is lacking in the SOA adoption domain. Therefore, a mixed method approach that combines both the qualitative and quantitative study could produce better and more comprehensive results. In addition, this study is more inclined towards identifying IT and business benefits. Consequently, the theory which emerged from this study may be inclined to provide these outcomes or benefits that can be achieved from the SOA adoption.

\section{CONCLUSION AND FUTURE WORK}

This study has successfully proven that Grounded Theory is an effective qualitative research method for software engineering research. Some theories 
related to SOA adoption were generated through Grounded Theory from interviewing and analyzing participants' perspectives focused on capturing their experiences in adopting and managing SOA practices. Even though using Grounded Theory is time-consuming and tedious, it managed to generate volumes of data and produced interesting and useful insights from the data gathered. The knowledge gained in this study has enriched existing knowledge on SOA adoption processes. In particular, there are four main contributions highlighted in this study. Firstly, findings from this study indicate that there are five main issues of SOA adoption. The issues are related to SOA knowledge, SOA infrastructure, SOA costing, SOA readiness and SOA documentation. This findings show that there is a lack of SOA adoption process guidelines and the identification of these issues are important particularly in assisting practitioners on matters related to SOA adoption. Secondly, the study has identified five main SOA adoption practices which are SOA technology, framework, platform, standards, and tools. Next, this study has also discussed SOA adoption levels which consist of five stages namely initial, adopted, implemented, evaluated, and optimized. Each level indicates the key process areas in achieving successful SOA adoption. Finally, the study has presented and described the benefits of SOA adoption based on two categories which are IT and business benefits. Theories generated from Grounded Theory has provided a foundation guideline for understanding the SOA adoption process. This guideline is useful when constructing a SOA adoption maturity model.

\section{ACKNOWLEDGEMENT}

This study was funded by the Ministry of Education, Malaysia under the Long Term Research Grant Scheme (LRGS/bu/2012/UUM/Teknologi Komunikasi dan Infomasi).

\section{REFERENCES}

Abdul Manan, M. (2013). Developing a framework and a scorecard method to measure the enterprise - wide SOA implementation readiness of an organisation. University of Wollongong. Retrieved from http://ro.uow. edu.au/cgi/viewcontent.cgi/article $=4869 \&$ context $=$ theses

Aldris, A., Nugroho, A., Lago, P., \& Visser, J. (2013). Measuring the degree of service orientation in proprietary SOA systems. In International Symposium on Service-Oriented System Engineering (pp. 233-244). doi.org/10.1109/SOSE.2013.63

Aljazzaf, Z. M., Capretz, M. A. M., \& Perry, M. (2016). Trust-based ServiceOriented Architecture. Journal of King Saud University - Computer and Information Sciences. doi.org/10.1016/j.jksuci.2015.12.003 
Amanatidis, T., \& Chatzigeorgiou, A. (2016). Studying the evolution of PHP web applications. Journal of Information and Software Technology, 72, 48-67. doi.org/10.1016/j.infsof.2015.11.009

Anthony, B. J., Majid, M. A., \& Romli, A. (2018). An empirical study on predictors of green sustainable software practices in Malaysian electronic Industries. Journal of Information and Communication Technology, 17(2), 347-391.

Baghdadi, Y. (2014). SOA Maturity Models: Guidance to Realize SOA. International Journal of Computer and Communication Engineering, 3(5), 372-378. doi.org/10.7763/IJCCE.2014.V3.352

Basias, N., Themistocleous, M., \& Morabito, V. (2015). A Decision Making Framework for SOA Adoption in e-Banking: A Case Study Approach. Journal of Economics, Business and Management, 3(1), 48-53. doi. org/10.7763/JOEBM.2015.V3.154

Baskerville, R., Cavallari, M., Hjort-Madsen, K., Pries-Heje, J., \& Sorrentino, M. (2005). Extensible architectures: The strategic value of service oriented architecture in banking. 13th European Conference on Information Systems (ECIS 2005), Paper 61. Retrieved from http:// aisel.aisnet.org/ecis2005/61/

Becker, A., Buxmann, P., \& Widjaja, T. (2009). Value potential and challenges of service-oriented architectures-A user and vendor perspective. Seventeenth European Conference on Information Systems (ECIS 2009), 616-628. Retrieved from http://search.ebscohost.com/login. aspx/direct=true $\& \mathrm{db}=$ epref\&AN=SECISEB.BJJI.FAF \&site

Blomstedt, F., Ferreira, L. L., Klisics, M., Chrysoulas, C., Soria, I. M. De, \& Morin, B. (2014). The Arrowhead Approach for SOA Application Development and Documentation. In Annual Conference of the IEEE Industrial Electronics Society. IEEE. doi.org/10.1109/ IECON.2014.7048877

Bluemke, I. (2014). Tool for Automatic Testing of Web Services, 2, 15531558. http://doi.org/10.15439/2014F93

Brien, L. O. (2009). A Framework for Scope, Cost and Effort Estimation for Service Oriented Architecture ( SOA ) Projects. In Australian Software Engineering Conference (pp. 101-110). doi.org/10.1109/ ASWEC.2009.35

Cao, L., \& Ramesh, B. (2008). Agile Requirements Engineering Practices: An Empirical Study. IEEE Software, 25(1), 60-67. doi.org/10.1109/ MS.2008.1

Ciganek, A. P., Haines, M. N. and Haseman, W. D. (2009). Service-Oriented Architecture Adoption: Key Factors and Approaches, Journal of Information Technology Management, 20(3), 42-54. 
Charmaz, K. (2000). Grounded theory: Objectivist and contructivist methods. In N. K. Denzin \& Y. S. Lincoln (Eds.), Handbook of Qualitative Research (pp. 509-535). London: Sage Publications, Inc.

CMMI Product Team. (2010). CMMI ${ }^{\circledR}$ for Services, Version 1.3 CMMI-SVC, V1.3 Improving processes for providing better services. Engineering, 520(520), 520. Retrieved from http://www.sei.cmu.edu/library/ abstracts/reports/10tr034.cfm

Damanpour, F., \& Daniel-Wischnevsky, J. (2006). Research on innovation in organizations: Distinguishing innovation-generating from innovation-adopting organizations. Journal of Engineering and Technology Management - JET-M, 23(4), 269-291. doi.org/10.1016/j. jengtecman.2006.08.002

Eckert, J., Bachhuber, M., Miede, A., Papageorgiou, A., \& Steinmetz, R. (2010). Readiness and maturity of service-oriented architectures in the German banking industry. In International Conference on Digital Ecosystems and Technologies (pp. 270-274).

El-gayar, O., \& Deokar, A. (2013). A semantic service-oriented architecture for distributed model management systems. Journal of Decision Support Systems, 55(1), 374-384. doi.org/10.1016/j.dss.2012.05.046

Elia, I. A., Laranjeiro, N., \& Vieira, M. (2014). Understanding interoperability issues of web service frameworks. In International Conference on Dependable Systems and Networks. http://doi.org/10.1109/ DSN.2014.40

Espí-beltrán, J. V., Gilart-iglesias, V., \& Ruiz-fernández, D. (2016). Integrated manufacturing enabling distributed manufacturing resources through SOA: The REST approach. Journal of Robotics and Computer Integrated Manufacturing. doi.org/10.1016/j.rcim.2016.09.007

Erl, T. (2005). Service-oriented architecture: Concepts, technology, and design. Prentice Hall.

Gbaffonou, B. A. D., Lapalme, J., \& Champagne, R. (2015). Service-Oriented Architecture: A Mapping Study. 2015 International Conference on Enterprise Systems (ES), 33-42. doi.org/10.1109/ES.2015.11

Glaser, B. (1992). Basics of grounded theory analysis: Emergence vs forcing. Sociology Press, Mill Valley.

Glaser, B., \& Holton, J. (2007). Remodeling Grounded Theory. In Historical social research, supplement (pp. 47-68).

Glaser, B., \& Strauss, A. (1967). The Discovery of Grounded Theory Strategies for Qualitative Research. New Jersey, USA: Aldine Transaction.

Graaf, K. A. De, Liang, P., Tang, A., \& Vliet, H. Van. (2015). How organisation of architecture documentation affects architectural knowledge retrieval. Journal of Science of Computer Programming, 1, 1-25. doi. org/10.1016/j.scico.2015.10.014 
Guest, G., Bunce, A., \& Johnson, L. (2006). How Many Interviews Are Enough?. Field Methods - FIELD METHOD. 18. 59-82. $10.1177 / 1525822$ X05279903.

Haines, M. N., \& Haseman, W. (2009). Service-oriented architecture adoption patterns. Proceedings of the 42nd Annual Hawaii International Conference on System Sciences, HICSS, 1-9. doi.org/10.1109/ HICSS.2009.388

Hamzah, M. H. I., Baharom, F., \& Mohd, H. (2017). A conceptual model for service-oriented architecture adoption maturity model. In International Conference on Computing and Informatics (pp. 139-145).

Hsiung, A., Rivelli, G., \& Hüttenegger, G. (2012). How to design a global SOA infrastructure - coping with challenges in a global context. In International Conference on Web Services. doi.org/10.1109/ ICWS.2012.22

Hoda, R., Noble, J., \& Marshall, S. (2012). Developing a grounded theory to explain the practices of self-organizing Agile teams. Empirical Software Engineering. doi.org/10.1007/s10664-011-9161-0

Inaganti, S., \& Aravamudan, S. (2007). SOA Maturity Model. BPTrends, (April), 1-23. doi.org/10.1007/978-3-319-02453-0

Joachim, N., Beimborn, D., \& Weitzel, T. (2011). An Instrument for Measuring SOA Maturity. ICIS 2011 Proceedings, 1-11. Retrieved from http:// aisel.aisnet.org/icis2011/proceedings/breakthroughideas/3/

Joachim, N. (2011). A literature review of research on service-oriented architectures (SOA): Characteristics, adoption determinants, governance mechanisms, and business impact. Americas Conference on Information Systems, 1-11.

José, D., Osinski, M., \& Hermann, R. (2017). The construction process of grounded theory in administration. Contaduría Y Administración, 62(3), 985-1000. doi.org/10.1016/j.cya.2016.06.012

Joukhadar, G., \& Rabhi, F. (2015). SOA in practice - A study of governance aspects. Information Systems Frontiers. doi.org/10.1007/s10796-0159607-9

Jovanovic, M., Mas, A., Mesquida, A., \& Lali, B. (2017). Transition of organizational roles in Agile transformation process: A. Journal of Systems and Software, 133, 174-194. doi.org/10.1016/j.jss.2017.07.008

Kontogiannis, K., Lewis, G. A., Smith, D. B., Litoiu, M., Muller, H., Schuster, S., \& Stroulia, E. (2007). The landscape of service-oriented systems: A research perspective. Systems Development in SOA Environments, 2007. SDSOA '07: ICSE Workshops 2007. doi.org/10.1109/SDSOA.2007.12

Konigsberger, J., Silcher, S., \& Mitschang, B. (2014). SOA-GovMM: A meta model for a comprehensive SOA governance repository. Proceedings of the 2014 IEEE 15th International Conference on Information Reuse and Integration, IEEE IRI 2014, 187-194. doi.org/10.1109/ IRI.2014.7051889 
Liu, J., \& Chen, W. (2017). FATDOG: Hadoop based Test Data Generation Tool for RESTful Web Service. In Annual Computer Software and Applications Conference (pp. 1-2). doi.org/10.1109/ COMPSAC.2017.124

Mazzarolo, C., Martins, V., Toffanello, A., \& Puttini, R. (2015). A method for SOA maturity assessment and improvement. IEEE Latin America Transactions, 13(1), 204-213. doi.org/10.1109/TLA.2015.7040649

Meier, F. (2006). Service Oriented Architecture Maturity Models : A guide to SOA Adoption. University of Skovde. Retrieved from http://his.divaportal.org/smash/get/diva2:2439/FULLTEXT01\&sa=X\&scisig=AAG Bfm0KJoWMWfrPvwBxKq_VQleCaxkngA\&oi=scholarr\&ei=V_Ww T4nFMMrB0QWJvIS6CQ\&ved=0CBsQgAMoAjAA

Niklas, K., Greenyer, J., \& Schneider, K. (2015). Towards application and evolution of model-based heuristics for improving SOA service design. Proceedings - 7th International Workshop on Modeling in Software Engineering, MiSE 2015, 60-65. http://doi.org/10.1109/MiSE.2015.18 Oracle. (2013). SOA Maturity Model - Guiding and Accelerating SOA Success. Pan, G., Zhang, L., Wu, Z., Li, S., Yang, L., Lin, M., \& Francis, S. (2014). Pervasive Service Bus: Smart SOA Infrastructure for Ambient Intelligence. IEEE Intelligent Systems, 52-60. doi.org/10.1109/ MIS.2012.119

Roger, E. (1995). Diffusion of innovations. Newyork Free Press. doi.org/ citeulike-article-id: 126680

Sekaran, U. \& Bougie, R. (2010). Research methods for business. New York: John Wiley \& Sons.

Shafinah, M., Fauziah, Aziz., Jamaliah. \& Haslina. (2016). An Exploratory Study on Secure Software Practices Among Software Practitioners in Malaysia. Journal of Telecommunication, Electronic and Computer Engineering, 8(8), 39-45

Sonic Software, Corporation; AmberPoint, Inc.; BearingPoint, Inc.; Systinet, C. (2005). A new Service-Oriented Architecture (SOA) Maturity Model. Retrieved from http://www.omg.org/soa/Uploaded Docs/SOA/ SOA_Maturity.pdf

Veger, M. (2008). A stage maturity model for the adoption of an enterprisewide service-oriented architecture (SMM-SOA): A multicase study research, 93. Retrieved from http://essay.utwente.n1/58516/

Welke, R., Hirschheim, R., \& Schwarz, A. (2011). Service-Oriented Architecture Maturity. IEE Computer Society, 44(February), 61-67. doi.org/10.1109/MC.2011.56

Wisdom, J. P., Chor, K. H. B., Hoagwood, K. E., \& Horwitz, S. M. (2014). Innovation adoption: A review of theories and constructs. Administration and Policy in Mental Health and Mental Health Services Research, 41(4), 480-502. doi.org/10.1007/s10488-013-0486-4 


\section{APPENDIX A}

Questionnaires adopted from research by Abdul Manan (2013) and Veger (2008).

1. Questions on demographic information.

a) What best describes your current position in your company?

b) How long have you been participating in SOA or service based projects?

c) Which sector does your organization primarily belong to?

d) How long has your organization been participating in SOA or service based projects?

2. Questions on SOA adoption issues.

a) Does your organization face any problems or issues in SOA adoption?

b) What are the main challenges in SOA adoption?

c) Has your organization evaluated the maturity level of SOA adoption?

d) Do you think defining the measurement goal(s) for evaluating the maturity of SOA adoption is important?

e) Can you provide examples of goals that have been defined to evaluate the maturity of SOA adoption?

f) Do you think achieving SOA benefits (e.g. reusability, integration, and cost reduction) is important?

3. Questions on SOA adoption best practices.

a) What are the SOA technologies that you have been practising and that you are familiar with?

b) Did you apply any SOA framework in constructing the SOA based application?

c) What are the SOA platforms that you have been practising and that you are familiar with?

d) What are the SOA standards that you have been practising and that you are aware of?

e) Did you use any tools in constructing the SOA-based application?

f) Can you specify the SOA lifecycle that you are aware of and familiar with?

g) How long does it usually take for you to be familiar and comfortable with SOA practices? 
4) Questions on SOA adoption maturity level.

a) How would you describe SOA awareness in your organization?

b) What SOA training does your organization offer?

c) How would you describe the SOA skills in your organization?

g) How would you describe the belief in the effectiveness of SOA in your organization?

d) How do you improve the maturity of SOA in your organization?

e) Does your organization have a team that performs assessments on SOA adoption?

f) Do you agree that there must be several levels that the SOA adopter must undergo to fully adopt SOA?

g) Do you agree with the following levels that an adopter must undergo in order to fully adopt SOA? (Initial, Adopted, Implemented, Evaluated and Optimized)

5) Questions on SOA adoption benefits.

a) Do you agree that an organization adopts SOA because of the benefits that it provides?

b) Do you agree that SOA adoption benefit should be categorized into IT and business benefits?

c) Do you think that collaboration and solid relationship between IT and business is important? 